Revista de Estudios Histórico-Jurídicos

[Sección historia de los dogmas]

XXXVII (Valparaíso, Chile, 2015)

[pp. 325 - 346]

\title{
Historia DEL OBJETO MATERIAL DEL DELITO DE FALSEDAD DOCUMENTAL PUNIBLE
}

[History of the Material Object of the Punishable Crime of Forgery]

\author{
Laura MAYer LuX* \\ Pontificia Universidad Católica de Valparaíso, Chile \\ Jaime Vera Vega** \\ Pontificia Universidad Católica de Valparaíso, Chile
}

\begin{abstract}
RESUMEN
El trabajo analiza, desde una perspectiva histórica, el documento como objeto material de los delitos de falsedad documental. Para ello, se examina la regulación habida en el derecho romano, en el derecho medieval y en algunos códigos que sirvieron de referencia al Código Penal chileno. También plantea la existencia de aspectos comunes en dichas regulaciones, de lo que se deriva un continuo en el desarrollo histórico del objeto material de las falsedades documentales punibles. Ello impide entender tales etapas de manera aislada, y llama más bien a considerar dicha evolución histórica como una unidad en el tiempo.

Palabras clave

Falsificación de documento - Falsificación de testamentos - Falsificación de edictos - Falsificación de documentos regios.
\end{abstract}

\begin{abstract}
This work analyses, from a historical approach, the document as the material object of forgery. To do this, Roman law regulations, Medieval law regulations and some codes used as basis for the Chilean Criminal Code are examined. It also establishes that there is something common in said legislations, from which a thread of continuity can be inferred from the historical development of the material object of the punishable crime of forgery. Said stages must not be understood individually; therefore, it rather urges us to consider said historical evolution as a unit in time.

KeYwords

Document forgery - Will forgery Edict forgery - Royal documents forgery.
\end{abstract}

RECIBIDO el 20 de enero y ACEPTADO el 30 de julio de 2015

* Profesora de derecho penal en la Pontificia Universidad Católica de Valparaíso. Dirección postal: Brasil 2950, Valparaíso, Chile. Correo electrónico: laura.mayer@ucv.cl.

** Profesor de derecho penal y procesal penal en la Pontificia Universidad Católica de Valparaíso. Dirección postal: Brasil 2950, Valparaíso, Chile. Correo electrónico: jaime.vera@ucv.cl. 


\section{INTRODUCCIÓN***}

A lo largo de la historia, los documentos han cumplido una función de suma importancia para las relaciones intersubjetivas y, dentro de ellas, para el tráfico jurídico. En este orden de ideas, el hombre ha necesitado contar con ciertos objetos que le permitan transmitir información a otros, en los más diversos ámbitos, v.gr. mensajes de la autoridad a sus súbditos; comunicaciones entre particulares que interactúan en el ámbito contractual; mensajes tendientes a constituir o reconocer determinados estados jurídicos -como los de heredero o paternidad-, entre otros.

Para propiciar la comunicación antes indicada, el ser humano ha debido recurrir a objetos con ciertos atributos bien determinados. En primer lugar, se ha tratado de objetos capaces de otorgar una cierta perdurabilidad ${ }^{1}$ a la información que se contiene en ellos. Esta capacidad de fijación se vincula con la relevancia que tiene la escrituración para las relaciones jurídicas, en comparación con el lenguaje oral y el gestual ${ }^{2}$. En efecto, como en el tráfico jurídico se busca consolidar ciertas situaciones, la transferencia de la información requiere un mecanismo de fijación que dé certeza a los sujetos ${ }^{3}$, mecanismo que en nuestra tradición jurídica ha sido, precisamente, la escrituración en determinados soportes. Por ejemplo, para efectuar una transferencia de bienes a menudo no basta con una transmisión verbal de información entre los interactuantes, sino que se requiere plasmar dichos contenidos de alguna manera. Esto permite una consolidación de los derechos que emanan del negocio que se documenta, pues el soporte puede ser utilizado para invocar su existencia frente a otros.

En segundo lugar, para fomentar la comunicación al interior del tráfico jurídico, se ha requerido contar con objetos que, además de perpetuar declaraciones del pensamiento humano, permitan atribuir tales declaraciones a su autor. Una condición fundamental para el funcionamiento del tráfico jurídico es que los intervinientes del mismo sepan quiénes están interactuando dentro de él. En

*** Los autores agradecen especialmente la valiosa colaboración recibida de parte de los profesores Alejandro Guzmán, Patricio Lazo, Ítalo Merello y Carlos Salinas para la elaboración del presente trabajo.

${ }^{1}$ Perdurabilidad que dependía, entre otras cosas, del material empleado para registrar los contenidos (cfr. MATEO SANZ, Antonio, Documentos administrativos como elementos de prueba en el proceso privado romano, en La prueba y medios de prueba: De Roma al derecho moderno. Actas del VI Congreso Iberoamericano y III Congreso Internacional de Derecho Romano [Madrid, Servicio de Publicaciones Universidad Rey Juan Carlos, 2000], p. 510), así como de las condiciones en que eran almacenados los respectivos soportes.

${ }^{2}$ En el mismo sentido LAzo, Patricio, La incertidumbre del texto en la experiencia juridica romana. A propósito de D.1,2,2,1-3, en Revista Chilena de Derecho, 41 (2014) 3, p. 1189 : "Aunque los sistemas jurídicos suelen admitir la vigencia de costumbres como una de sus partes integrantes, el peso que llegan a tener no es equiparable al de los textos [...]".

${ }^{3}$ Cfr. Martínez Martínez, Faustino, El tránsito de la oralidad hacia la escritura en la experiencia jurídica del siglo XIII: ejemplo sajón e hipótesis castellana (parte primera), en Cuadernos de Historia del Derecho, 13 (2006), pp. 160 ss., quien destaca que el texto escrito, además de otorgar certeza, permite la reproducción, transmisión e interpretación de sus contenidos. Específicamente sobre el problema de la falta de certeza respecto de la ley y el Derecho, en atención a la ausencia de textos jurídicos, LAzo, Patricio, cit. (n. 2), pp. 1191 ss. 
otros términos, el anonimato es un fenómeno que entorpece el desarrollo de las relaciones jurídicas entre los individuos. Así, por ejemplo, en una actuación de la autoridad, como la dictación de un decreto, conocer la identidad de su autor permite establecer si está dotado de las facultades para emitirlo. En un contrato, conocer la identidad de las partes permite determinar si están afectadas por una incapacidad. En fin, en la constitución de una sociedad, conocer la identidad de los socios permite establecer quiénes son sus creadores y en quiénes se van a radicar los efectos jurídicos provenientes de las actuaciones de la misma. Para atribuir tales declaraciones a un autor determinado, el tráfico jurídico se ha valido de ciertos signos, que también quedan plasmados en el soporte documental, v.gr. timbres o sellos, firmas, huellas dactilares, entre otros.

En tercer lugar, las relaciones de los individuos en el marco del tráfico jurídico necesitan de una mínima certeza sobre la efectividad de la información contenida en los soportes documentales. En virtud de dicha efectividad es posible acreditar, frente a otros, una serie de extremos de la relación jurídica de que se trate, como su creación, sus modificaciones o su extinción. De esta forma, la consolidación de las relaciones al interior del tráfico no sólo requiere de medios que garanticen perdurabilidad e identificación de los autores de los respectivos mensajes; también necesita que la información comunicada trascienda como algo que realmente sucedió de la manera en que se indica en el soporte. Por ejemplo, tratándose de las formas testamentarias en el derecho romano clásico, dicho efecto se conseguía a través de un signo bien concreto, a saber, el uso de tablillas selladas ${ }^{4}$. Gracias a su empleo, que a veces debía ir unido al cumplimiento de otros requisitos, podía partirse de la base de que el testador efectivamente había designado heredero a quien figuraba en las tablillas selladas.

También es una constante, a lo largo de la historia, la atribución de efectos de validez general a determinados soportes documentales. Tal validez general normalmente va unida al cumplimiento de ciertas formas, relativas a las características mismas del soporte, a la presencia de determinadas cláusulas, a la intervención de ministros de fe o sujetos dotados de auctoritas, entre otros. Dicho fenómeno se vincula con la necesidad que existe, en el tráfico jurídico, de atribuir efectos erga omnes a ciertos contenidos, sobre la base de una confianza general acerca de su efectividad. Así ocurre, por ejemplo, con la información certificada por escribanos, notarios o ministros de fe, contenida en soportes escriturados, cuya efectividad puede predicarse no sólo respecto de sus otorgantes, sino que, en general, respecto de cualquier interactuante en el tráfico.

De lo expuesto queda en evidencia la importancia que los documentos han tenido para el desarrollo del tráfico jurídico a lo largo de la historia. Precisamente

${ }^{4}$ Véase GuZmán BRITO, Alejandro, Derecho privado romano (reimp. de la 1a edición, Santiago, Editorial Jurídica de Chile, 1997), II, pp. 417 s. Otro ejemplo lo proporciona CarVAJAL, PatriciovIgnacio, El "receptum nautarum" y el papiro Grenf. II 108, en Revista de Estudios Histórico-Jurídicos, 28 (Valparaíso, Chile, 2006), pp. 145 y 155, quien alude al documento que habría sido empleado como recibo, otorgado por el cargador al navegante-transportista, a fin de que "[...] acreditase, de ser necesario, la adecuada restitución de los bienes transportados [...]” en el contexto del tráfico marítimo. 
esta importancia, ha motivado la creación de normas protectoras del documento en distintos ámbitos, tendientes a sancionar hipótesis de alteración del soporte y de su contenido. Dentro de ellas destacan las normas penales que prevén comportamientos falsarios, y que, en distintas épocas, han originado la reacción más drástica ${ }^{5}$ frente a la alteración de documentos al interior del tráfico.

El presente trabajo efectuará un análisis histórico jurídico de la institución del documento como objeto material de delitos de falsedad ${ }^{6}$. Por objeto material entendemos, en términos generales, la persona o cosa sobre la cual recae el comportamiento delictivo ${ }^{7}$.

Con dicha finalidad, el estudio comenzará en el derecho romano, debido a que si bien en algunas de las principales expresiones del denominado derecho cuneiforme existieron soportes de carácter documental, similares a los de épocas posteriores, no hubo una normativa que de manera clara y categórica penalizara hipótesis de falsedad recaída en documentos ${ }^{8}$. En otras palabras, no obstante puede afirmarse que "[l]a historia del documento empieza a partir de la invención de la escritura", la historia del documento como objeto material de comportamientos falsarios comienza cuando, precisamente, se crean normas jurídicas destinadas a la represión de dichas conductas.

El estudio continuará con el objeto material de las falsedades documentales en el derecho medieval para, finalmente, abordar la época de la codificación y la recepción que el Código Penal chileno llevó a cabo en esta materia.

Ahora bien, este trabajo sólo abordará la regulación penal de algunos documentos en las fuentes que se utilizarán como referencia, constituyendo el criterio de selección de los mismos la importancia que tales objetos tuvieron en el desarrollo histórico del objeto material de los delitos de falsedad documental. Hacemos esta prevención con el fin de establecer que el presente estudio sólo

\footnotetext{
${ }^{5}$ Que incluso en algunos casos correspondía a la pena de muerte. Con alusión a la lex Cornelia de falsis, por ejemplo, ARrimadas GarCía, Alfonso, Consideraciones en torno a la falsificación de moneda, en Dactual. VII Congreso Internacional y XIberoamericano de Derecho Romano (Madrid, Edisofer, 2005), p. 103 n. 3, con referencias ulteriores.

${ }^{6}$ Por tanto, el estudio no se centrará en la historia de los delitos de falsedad documental (para dicha historia, fundamental, AlEJANDrE, Juan Antonio, Estudio histórico del delito de falsedad documental, en Anuario de Historia del Derecho Español, 43 [Madrid, 1972], pp. 117 ss.; cfr. asimismo Rojas, Luis Emilio, Historia dogmática de la falsedad documental, en Revista de Derecho de la Pontificia Universidad Católica de Valparaíso, 39 [Valparaíso, Chile, 2012], pp. 545 ss.), ni mucho menos en la historia de las falsedades, la cual, por cierto, excede con creces las pretensiones del presente trabajo.

${ }^{7}$ Véase por todos Cury, Enrique, Derecho penal. Parte general (10 a edición, Santiago, Ediciones Jurídicas UC, 2011), p. 290.

${ }^{8}$ En ese orden de ideas, quizás la única hipótesis clara de falsedad documental contenida en las Leyes de Manú fue la consistente en falsificar edictos reales (cfr. BüHLER, G., cit. [n. 8], p. 382 , relativa a la regla 232 del libro IX), la cual, comparada con la multiplicidad de supuestos de falso testimonio o de otros delitos, como el robo, parece tener un carácter más bien anecdótico.

${ }^{9}$ Díaz-Melián de Hanisch, Mafalda, Medios de prueba. El documento: evolución histórica. Roma, en La prueba y medios de prueba: De Roma al derecho moderno. Actas del VI Congreso Iberoamericano y III Congreso Internacional de Derecho Romano (Madrid, Servicio de Publicaciones Universidad Rey Juan Carlos, 2000), pp. 196 s.
} 
analizará el documento en tanto objeto material de los delitos de falsedad y no como institución general del derecho.

\section{El objeto material De LaS falsedades documentales en Roma}

Según Núñez Martí, en el derecho romano los documentos escritos cumplieron una función secundaria, en comparación con otros medios probatorios -v.gr. los testigos- situación que habría cambiado a partir de la época post-clásica, "como consecuencia del influjo sobre Roma de la práctica contractual escrita en las provincias"10. Mayer-Maly, por su parte, señala las razones por las cuales, todavía en el derecho romano clásico, las actuaciones verbales y, dentro de ellas, principalmente las fórmulas habladas, cumplieron un rol muy destacado en relación con las piezas escritas. A su juicio, el clima italiano hacía difícil la conservación de los documentos, a lo que añade que el analfabetismo aún se encontraba muy difundido y que la redacción de importantes textos era monopolizada por los sacerdotes ${ }^{11}$.

Lo anterior puede explicar que la falsedad documental en Roma haya surgido y se haya desarrollado en forma paulatina, respecto de soportes concretos. Como veremos, la falsedad documental comenzó a reprimirse respecto de testamentos escritos $^{12}$, para luego extenderse a otros objetos específicos, en la medida en que la documentación de los respectivos negocios jurídicos iba adquiriendo una mayor relevancia en la sociedad romana. De allí que no se criminalizara, en términos generales y abstractos, la falsedad recaída en cualquier clase de documento.

La doctrina coincide en que el primer texto legal destinado a reprimir delitos falsarios en el derecho penal romano fue la lex Cornelia testamentaria nummaria y sus modificaciones posteriores ${ }^{13}$. Con todo, existe discrepancia en torno a varios aspectos de dicha ley, debido a que su conocimiento no es directo, sino que procede

\footnotetext{
${ }^{10}$ NúŃnz MarTí, Amparo, Crimen falsi: Derecho romano y nueva ley de enjuiciamiento civil, en La prueba y medios de prueba: De Roma al derecho moderno. Actas del VI Congreso Iberoamericano y III Congreso Internacional de Derecho Romano (Madrid, Servicio de Publicaciones Universidad Rey Juan Carlos, 2000), p. 532.

${ }^{11}$ Cfr. Mayer-Maly, Theo, "Transscribere", en Avenarius, Martin - Meyer-Pritzl, Rudolf - MölLER, Cosima (editores), "Ars Iuris". Festschrift für Okko Behrends zum 70. Geburtstag (Göttingen, Wallstein, 2009), p. 387.

${ }^{12}$ Pues, como destaca Marlasca Martínez, Olga, La regulación de la falsificación de los documentos en el derecho romano y en la Ley de los Visigodos, en Estudios de Deusto. Revista de la Universidad de Deusto, 47 (1999) 1, pp. 211 s., la emisión de la lex Cornelia de falsis coincidió con esta forma testamentaria que, a nuestro juicio, vino a complementar otras existentes a la época, como el testamento in calatis comitiis, el testamento celebrado bajo la fórmula per aes et libram o el testamento in procinctu, caracterizados por otorgarse de manera oral.

${ }^{13}$ Cfr. Mommsen, Teodoro, El derecho penal romano (traducción castellana de Dorado, P., Madrid, La España Moderna, 1898), II, pp. 139 ss. y 142. Véase también FerRuccio, Giuseppino, Diritto penale romano (I singoli reati) (Padova, R. Zannoni, 1932), II, p. 168; y SANTALUCIA, Bernardo, Studi di diritto penale romano (Roma, L'Erma di Bretschneider, 1994), pp. 77 ss.
} 
de las referencias contenidas en las Institutiones de Justiniano ${ }^{14}$, los Digesta ${ }^{15}$, el Codex ${ }^{16}$ y las Sententiae de Paulo ${ }^{17}$.

La opinión más autorizada indica que la lex Cornelia testamentaria nummaria fue emitida el año 81 a. C. y que su objeto fue castigar la falsedad de testamentos y monedas, pasando luego a denominarse de falsis, en atención al amplio campo de aplicación que alcanzó ${ }^{18}$. Que en sus orígenes la falsedad documental haya quedado circunscrita a los comportamientos falsarios recaídos en testamentos habría obedecido a la relevancia que tuvieron los testamentos en el tráfico jurídico romano ya en la época de dictación de la lex Cornelia ${ }^{19}$.

En relación con el testamento, en tanto objeto material de comportamientos falsarios, cabe hacer presente que éste generalmente fue escrito en varias tablillas plegables de madera encerada ${ }^{20}$, aceptándose, sin embargo, el empleo de otra clase de materiales o soportes, ya sea nuevos o usados ${ }^{21}$, como, por ejemplo, papiro (charta), pergamino (membrana) o cuero (corius) ${ }^{22}$. Con todo, desde un punto de vista histórico, se sostiene que si bien a la época de dictación de la lex Cornelia testamentaria nummaria los testamentos fueron, efectivamente, confeccionados en tabulae ceratae o cerae, dicho soporte habría sido sustituido, lentamente, por el papiro ${ }^{23}$.

Una vez redactado el documento formado por las tablillas, éstas "son ligadas mediante un cordón de lino que se pasa por forados hechos en sus extremos, y que se anuda apropiadamente, de modo que no pueda abrirse aquél sin destruir el cordón” ${ }^{24}$. Finalmente, se exigía, para el perfeccionamiento del testamento -salvo que el testador haya sido un militar-, que todos los testigos hubieran colocado sus sellos personales (signa) sobre cera depositada encima del cordón que unía las tablillas de madera o el material empleado para su confección ${ }^{25}$.

Los comportamientos falsarios relativos a testamentos fueron los siguientes: hacer (scribere) o sellar (signare) un testamento falso, o hacer de él uso judicial (recitare); fuera de otros actos dolosos recaídos en un testamento auténtico, tales como sustraerlo (amovere), ocultarlo (celare), robarlo (eripere), destruirlo (delere),

${ }^{14}$ Cfr. Institutiones de Justiniano 4,18,7.

${ }^{15}$ Cfr. Dig. 48,10.

${ }^{16}$ Cfr. Cod. Iust. 9,22.

${ }^{17}$ Cfr. Pauli Sententiae 4,7,1; 4,7,3; 4,7,4; 4,7,5; 5,25,1.

${ }^{18}$ Cfr. D'Ors, Álvaro, Contribuciones a la historia del "crimen falsi", en Studi in onore di Edoardo Volterra (Milano, Giuffrè, 1969), II, p. 544.

${ }^{19}$ Véase ARCHI, Gian Gualberto, Problemi in tema di falso nel diritto romano, en EL MISMO, Scritti di diritto romano (Milano, Giuffrè, 1981), III, pp. 1533 y 1580; también AleJANDre, Juan Antonio, cit. (n. 6), p. 128.

${ }^{20}$ Véase MARINO, Fabio, Il falso testamentario nel diritto romano, en MAYER-MALY, Theo y otros (editores), en Zeitschrift der Savigny-Stiftung, rom. Abt., 105 (1988), pp. 637 s.

${ }^{21}$ Esto es, soportes que ya habían sido escritos, pero cuya escritura había sido borrada para volver a utilizarlos. Cfr. GUZMÁN BRITO, A., cit. (n. 4), p. 424, con referencias ulteriores.

${ }^{22}$ Cfr. GuZMÁn Brito, A., cit. (n. 4), p. 424, con referencias ulteriores; también ArCHI, Gian Gualberto, cit. (n. 20), p. 1540.

${ }^{23}$ Cfr. Marino, Fabio, cit. (n. 21), p. 637.

${ }^{24}$ GuZmán Brito, A., cit. (n. 4), p. 424.

${ }^{25}$ Cfr. Guzmán Brito, A., cit. (n. 4), pp. 424 y s. 
alterar su escritura (interlinere), cambiarlo por otro (subicere) o abrirlo indebidamente (resignare). Por otra parte, la misma ley ${ }^{26}$ castigó la falsificación de sellos en general (signum adulterinum), distinguiendo entre esculpir su cuño (sculpere), hacerlo (facere) y extraerlo (exprimere) ${ }^{27}$.

En la evolución histórica del objeto material de las falsedades documentales, el siguiente hito lo marca la dictación del senadoconsulto Liboniano, del año 16 d.C. Su importancia radica en haber extendido el castigo de la falsedad recaída en testamentos a aquellas referidas a otra clase de documentos sellados ${ }^{28}$, a saber, los denominados documentos "cum consignatione"29.

Los documentos que tenían signum o signa se caracterizaban por estar sellados, lo cual era entendido como una garantía de integridad y autenticidad del escrito, de una manera similar a como hoy en día se interpreta la intervención de un funcionario - por ejemplo, en calidad de fedatario- en el otorgamiento de un documento público. De ahí que se castigara tanto a quien falsificaba un documento provisto de signum, como a quien destruía los sellos de un documento de carácter auténtico.

Más tarde, la represión penal de la falsedad se habría extendido incluso a documentos "sine consignatione", cuya existencia conocemos en virtud de dos fragmentos del Digesto atribuidos a Marciano ${ }^{30}$ y Paulo $^{31}$. Su supuesto principal, según d'Ors, "debía de ser el de la documentación burocrática” ${ }^{32}$. Estas extensiones del crimen falsi a diversos objetos pueden ser entendidas como expresión de un fenómeno que venía produciéndose en la sociedad romana hacia fines del Periodo Clásico, esto es, el paulatino reemplazo de fórmulas sacramentales, como la stipulatio, por documentación en un sentido cercano a como la comprendemos hoy.

Dentro de la documentación burocrática, como objeto material de comportamientos falsarios, destaca muy especialmente la recaída en edictos. Su alteración, en el Digesto, no es referida por Marciano ni por Paulo, sino que aparece en un

${ }^{26}$ Para reconstruir el catálogo de comportamientos falsarios que podían recaer sobre un testamento, es necesario considerar diversos fragmentos de las Pauli Sententiae, a saber, 4,7,1: "Qui testamentum falsum scripserit recitauerit subiecerit signauerit suppresserit amouerit resignauerit deleuerit, poena legis Corneliae de falsis tenebitur [...]"; 4,7,3: "Testamentum supprimit, qui sciens prudensque tabulas testamenti in fraudem heredum uel legatariorum fideiuecommissariorum aut libertatium non profert"; 4,7,4: "Supprimere tabulas uidetur, qui cum habeat et proferre possit, eas proferre non curat"; 4,7,5: "Codicilli quoque si lateant nec proferantur, supprimi uidebuntu"; 5,25,1: "Lege Cornelia testamentaria [tenentur :] qui testamentum quodue aliud instrumentum falsum sciens dolo malo scripserit recitauerit subiecerit suppresserit amouerit resignauerit deleuerit [...]".

${ }^{27}$ Cfr. D’Ors, A., cit. (n. 19), pp. 545 s.

${ }^{28}$ Véase Dig. 48,10,16,1: "Paulus respondit legis Corneliae poena omnes teneri, qui etiam extra testamenta cetera falsa signassent".

${ }^{29}$ Sobre esta materia, más ampliamente, D’Ors, A., cit. (n. 19), pp. 547 ss.

${ }^{30}$ Véase Dig. 48,10,1,4: "Qui in rationibus tabulis cerisve vel alia qua re sine consignatione falsum fecerint vel rem amoverint, perinde ex his causis, atque si erant falsarii, puniuntur".

${ }^{31}$ Véase Dig. 48,10,16,2: "Sed et ceteros, qui in rationibus tabulis litteris publicis aliave qua re sine consignatione falsum fecerunt vel, ut verum non appareat, quid celaverunt subripuerunt deleverunt subiecerunt resignaverunt, eadem poena adfici solere dubium non esse".

${ }^{32}$ D'Ors, A., cit. (n. 19), p. 548. 
fragmento de Modestino ${ }^{33}$. Según Domingo, existen también algunos fragmentos del Digesto atribuidos a Ulpiano que, como veremos, ampliarían la figura delictiva a comportamientos que no son falsarios ${ }^{34}$.

En comparación con la falsedad testamentaria, la relativa a los edictos no ha sido abordada ni por el mismo número de penalistas ni con igual profundidad que tratándose de los testamentos. Por lo mismo, su análisis se encuentra menos documentado que el referido a la falsificación testamentaria y es acometido, fundamentalmente, por romanistas e historiadores del derecho.

La acción de albo corrupto, que los protegía, constituyó una acción popular, cuyo carácter se fundaba en la lesión de la maiestas praetoris ${ }^{35} \mathrm{y}$, por ende, de la República ${ }^{36}$. Ésta, sólo podía ejercerse cuando el objeto material del comportamiento falsario era un edicto perpetuo, esto es, aquel "que subsiste durante el imperio del pretor y se observa en todos los negocios" ${ }^{37}$. En cambio, tratándose de un edicto repentino (es decir, aquel dictado con posterioridad al del inicio de la magistratura), se concedía únicamente una acción privada, destinada a perseguir la injuria ocasionada al particular ${ }^{38}$.

En relación con los comportamientos falsarios recaídos en edictos, la acción de albo corrupto podía dirigirse contra aquel que borraba el albo o album del pretor $^{39}$. Desde el punto de vista del material y de la escrituración empleados, el album habría sido un "fondo blanco" ${ }^{40} \mathrm{y}$, concretamente, una tablilla "encalada" 41

\footnotetext{
${ }^{33}$ Cfr. Dig. 48,10,32,1: "Hodie qui edicta proposita dolo malo corrumpunt, falsi poena plectuntur".

${ }^{34} \mathrm{Cfr}$. Domingo, Rafael, Estudios sobre el primer titulo del edicto pretorio. Palingenesia y reconstrucción (Santiago de Compostela, Servicio de Publicaciones e Intercambio Científico Campus Universitario, 1995), III, p. 87.

${ }^{35} \mathrm{Cfr}$. Domingo, Rafael, Observaciones para una nueva palingenesia del primer titulo del edicto perpetuo, en Escritos jurídicos en memoria de Luis Mateo Rodríguez (Santander, Universidad de Cantabria, Facultad de Derecho, 1993), II: "Derecho Privado", p. 112.

${ }^{36} \mathrm{Cfr}$. VINNIO, Arnoldo, Comentario académico y forense del célebre jurisconsulto Arnoldo Vinnio á los cuatro libros de las instituciones imperiales de Justiniano (Barcelona, Librería de D. J. Oliveres, 1867), II, p. 429.

${ }^{37}$ VINNIO, A., cit. (n. 37), p. 429.

${ }^{38}$ Cfr. VINNIO, Arnoldo, cit. (n. 37), p. 429.

${ }^{39}$ Véase Dig. 2,1,7,2: "Quod si dum proponitur vel ante propositionem quis corruperit, edicti quidem verba cessabunt, Pomponius autem ait sententiam edicti porrigendam esse ad haec"; y Dig. 2,1,7,5: "Hoc vero edicto tenetur et qui tollit, quamvis non corruperit: item et qui suis manibus facit et qui alii mandat. sed si alius sine dolo malo fecit, alius dolo malo mandavit, qui mandavit tenebitur: si uterque dolo malo fecerit, ambo tenebuntur: nam et si plures fecerint vel corruperint vel mandaverint, omnes tenebuntur".

${ }^{40}$ Domingo, R., Observaciones, cit. (n. 36), p. 113.

${ }^{41}$ D'Ors, Xavier, Antología de textos jurídicos de Roma (Madrid, Akal, 2001), p. 171.
} 
o "blanqueada" 42 , en la que se escribía el edicto utilizando "grandes letras" ${ }^{43}$, a fin de que el público pudiese conocerlo ${ }^{44}$ y leerlo "más fácilmente" ${ }^{45}$. Guarino pone de relieve que entre los siglos II y III el edicto no sólo se escribió en el album, sino que también fue fijado en otra clase de soportes, como el papiro, el pergamino y las tablillas de madera ${ }^{46}$. Desde el punto de vista de su difusión, en cambio, el edicto se habría expuesto públicamente fijado o colgado ${ }^{47}$ en un muro, tanto dentro de Roma, como en los municipios itálicos ${ }^{48}$.

En cuanto a la manera de presentar el contenido del edicto, el título edictal "[estaba] formado por una rúbrica que le da[ba] contenido" ${ }^{49}$. Las rúbricas, a su vez, "podían comprender varios edictos, con una o varias cláusulas cada uno" Domingo puntualiza que "sólo están rubricados los títulos edictales, pero no los distintos edictos que se hallaban bajo tales rúbricas" ${ }^{51}$. El mismo Domingo aclara que "si bien en sus orígenes la rúbrica fue siempre roja” -y de allí su nombre, proveniente de rubrum - "no es esencial al concepto de rúbrica el tener este color" 52 . Ello resulta confirmado por el hecho de que las leyes también fueron escritas sobre materiales como el bronce, en los que "no era posible la utilización del rojo" 53.

En cuanto a los comportamientos sancionados, se establecían hipótesis consistentes en corromper o romper ${ }^{54}$ o bien, borrar o alterar ${ }^{55}$ lo establecido en el

${ }^{42}$ Vinnio, A., cit. (n. 37), p. 429. En el mismo sentido, por ejemplo, CASTRO SÁENZ, Alfonso, Compendio histórico de derecho romano. Historia de la cultura jurídica europea (3a edición, Madrid, Tébar, 2006), I, p. 313; así como HeINECIO, J., Elementos del derecho romano según el orden de las Instituciones (traducción castellana de Vicente, J., Madrid, Imprenta de Don Pedro Sanz y Sanz, 1842), p. 340 n. 1168, destacando que, en cambio, según otros autores, el edicto del pretor debía su nombre (album), no a que la tabla empleada haya sido blanca, sino a que las letras con las que se escribía sobre dicha tabla habrían sido blancas. No hemos podido acceder a la opinión de tales autores ni a los fundamentos que habrían esgrimido para sustentarla. Sin embargo, tanto las fuentes como los planteamientos de la doctrina más autorizada nos llevan a concluir que la tesis correcta es la que vincula el nombre de album con el soporte material y no con las letras escritas sobre el mismo.

${ }^{43}$ Heinecio, J., cit. (n. 43), p. 340 n. 1168.

${ }^{44}$ Cfr. Vinnio, A., cit. (n. 37), p. 429; también De la Rada y Delgado, Juan de Dios, Elementos de derecho romano (Madrid, Imprenta de Repullés, 1857), II, p. 235.

${ }^{45}$ Heinecio, J., cit. (n. 43), p. 340 n. 1168.

${ }^{46}$ Véase Guarino, Antonio, De albo corrupto, en Index. Quaderni camerti di studi romanistici. International Survey of Roman Law, Omaggio a Francesco de Martino (Napoli, Jovene, 1990), p. 276.

${ }^{47}$ Véase Hoepfner, Ludwig Julius Friedrich, Theoretisch-practischer Commentar über die Heineccischen Institutionen nach deren neuesten Ausgabe ( $8^{a}$ edición, revisada, anotada y aumentada por Weber, Adolph Dieterich, Frankfurt am Main, s. e., 1804), p. 1096.

${ }^{48}$ Cfr. D'Ors, X., cit. (n. 42), p. 171.

${ }^{49}$ Domingo, Rafael, Sobre las supuestas rúbricas edictales en el edicto del pretor, en Zeitschrift der Savigny-Stiftung für Rechtsgeschichte, Rom. Abt, 108 (1991), p. 290.

${ }^{50}$ D'Ors, X., cit. (n. 42), p. 172.

${ }^{51}$ Domingo, Rafael, Sobre las supuestas rúbricas edictales, cit. (n. 50), p. 290.

${ }^{52}$ Ibíd., p. 290.

${ }^{53}$ Ibíd., p. 290.

${ }^{54}$ Véase Hoepfaner, L. J. F., cit. (n. 48), p. 1096.

${ }^{55}$ Véase De la Rada y Delgado, J. de D., cit. (n. 45), p. 235. 
edicto; mandar a otro a que lo borrara o alterara ${ }^{56}$; quitar el edicto o mandar a otro a quitarlo ${ }^{57}$, aunque ello no implicara borrarlo o alterarlo ${ }^{58}$. Como afirma Hugo, la corrupción debía ser hecha de mala fe (dolosamente), a fin de evitar un ejercicio de la acción contra quienes, legítimamente -por ejemplo, en virtud de una autorización- introducían alteraciones o cambios al edicto ${ }^{59}$.

\section{El objeto material de las falsedades documentales en la EdAD MEdia}

Respecto del objeto material de comportamientos falsarios durante la Edad Media, debemos partir con una prevención. Se trata ésta de una época sumamente extensa desde el punto de vista temporal, en relación con la cual existen fuentes fragmentarias de la normativa aplicable y en la que abundan periodos en los que lisa y llanamente no existe certeza sobre cuál era dicha normativa. Por ello, hemos seleccionado algunas fuentes medievales, que nos han parecido especialmente relevantes, ya que contemplan el castigo de falsedades recaídas en objetos materiales específicos de carácter documental. Consiguientemente, más que efectuar una relación de fuentes normativas, llevaremos a cabo un análisis de particulares objetos materiales contenidos en determinadas fuentes medievales.

Además, por la importancia que tienen para la siguiente etapa, dedicada a la codificación y, particularmente, a la operada en la legislación chilena, es que hemos seleccionado algunas fuentes españolas de referencia. Otras fuentes medievales, que tradicionalmente se consultan en estudios históricos del derecho -como la Lex Romana Visigothorum-, no obstante contienen regulaciones en materia de falsedad documental, no representan un cambio significativo respecto de la normativa romana que se analizó en el apartado anterior. Más bien lo que hacen es recoger la regulación que sobre el punto establecía la lex Cornelia ${ }^{60}$.

Ahora bien, la influencia de la regulación romana relativa a las falsedades documentales se advierte claramente en algunos de los cuerpos legales dictados por los Visigodos. Según Marlasca, existe una continuidad entre la regulación romana y la visigoda sobre los comportamientos falsarios recaídos en documentos, debido a que los godos "aceptaron de los romanos, entre otras muchas instituciones, el préstamo con interés, el testamento, los impedimentos matrimoniales de parentesco y, sobre todo, el múltiple empleo de documentos escritos en la vida jurídica" ${ }^{61}$. Ejemplo paradigmático de ese continuo es la normativa contenida en el Liber iudiciorum que, como es sabido, se tradujo en el siglo XIII al castellano con la denominación de Fuero Juzgo.

\footnotetext{
${ }^{56}$ Cfr. Díaz Bautista, Antonio, La acumulación de responsabilidades “ex delicto” en el Código de las "Siete Partidas", en Glossae. Revista de Historia del Derecho Europeo, 3 (1992), p. 130.

${ }^{57}$ Cfr. Vinnio, A., cit. (n. 37), p. 429; en términos similares Hoepfner, L. J. F., cit. (n. 4847), p. 1096, haciendo referencia a la conducta consistente en "llevarse" ("wegtragen") el edicto.

${ }^{58}$ Véase Díaz Bautista, A., cit. (n. 57), p. 130.

${ }^{59}$ Véase Hugo, Gustavo, Historia del derecho romano (traducción castellana de Casado Tello, M., Madrid, Establecimiento Tipográfico de D. R. R. de Rivera, 1850), pp. 357 s.

${ }^{60}$ Sobre la regulación de las falsedades documentales en leyes medievales bárbaras, véase Quintano Ripollés, Antonio, La falsedad documental (Madrid, Reus, 1952), p. 35.

${ }^{61}$ Marlasca Martínez, O., cit. (n. 13), p. 222.
} 
Dicha regulación estableció la siguiente sistemática para el objeto material de los delitos falsarios: documentos regios, por una parte, y documentos de otra índole (o que no tenían el carácter de regios), por la otra. En cuanto a los documentos regios, el comportamiento falsario podía recaer tanto en las escrituras emanadas del rey, incluidas sus leyes, como en el sello real. Cabe hacer presente que los documentos regios, en tanto objeto material de comportamientos falsarios, aparecen nítidamente con la normativa visigoda. A diferencia de ella, en el sistema romano el castigo de documentos equiparables a los documentos regios se hallaba confundido con el de otros objetos materiales ${ }^{62}$.

En relación con las conductas sancionadas respecto de los documentos regios, destacan los supuestos consistentes en mudar, deshacer o anular el documento, así como el de añadir algo a su contenido ${ }^{63}$. Fuera de ellos, se consagra una hipótesis que equivale al uso de un documento regio previamente falsificado (en específico, mostrar a sabiendas el falso documento regio $)^{64}$, así como un caso de falsedad de leyes emanadas del monarca ${ }^{65}$.

En cuanto a los documentos de otra índole, esto es, aquellos que no tenían el carácter de regios, el Liber iudiciorum no especifica las particularidades de los mismos, lo que sugiere que éstos habrían tenido un carácter residual respecto de los documentos regios. Como sea, tratándose de documentos que no tenían el carácter de regios, el comportamiento falsario podía recaer tanto en escrituras -a las que pueden agregarse cartas-, como en sellos o señales ${ }^{66}$.

En relación con las conductas sancionadas respecto de los documentos que no tenían el carácter de regios, destaca el supuesto consistente en hacer o forjar, usar en juicio, deshacer o alterar la verdad, romper o destruir, así como hurtar ${ }^{67}$.

Una característica que se advierte en esta época histórica respecto del objeto material de los comportamientos falsarios, es la "generalización" del mismo. En efecto, a diferencia de lo que puede constatarse a partir del estatuto de las falsedades documentales en la lex Cornelia y sus posteriores ampliaciones, en que se reprime

${ }^{62}$ Véase Alejandre, J. A., cit. (n. 6), p. 160, con referencias ulteriores.

${ }^{63} \mathrm{Cfr}$. Liber iudiciorum 7,5,1: "Hi, qui in auctoritatibus nostris vel preceptionibus aliquid mutaverint, diluerint, subtraxerint, vel interposuerint, vel tempus aut diem mutaverint, sive designaverint, et qui signum adulterinum sculpserint vel impresserint: honestior mediam partem facultatum suarum amittat, fisci commodis profuturam; minor vero persona manum perdat, per quam tantum crimen admisit. Quod si contingat illos auditores vel iudices mori, ad quos audientia vel iussio destinata fuerat: aut episcopo loci, aut alio episcopo, vel iudicibus vicinis territorii illius, ubi iussum fuerat, negotium terminare liceat, et datam preceptionem offerre, et eorum iudicio negotium legaliter ac iustissime ordinare".

${ }^{64} \mathrm{Cfr}$. Liber Iudiciorum 7,5,3. Nótese que en la rúbrica de dicho comportamiento también se alude a la falsedad de documentos del juez.

${ }^{65}$ Cfr. Liber Iudiciorum 7,5,9. Véase LaLINDE ABADÍA, Jesús, Iniciación histórica al derecho español ( $2^{a}$ edición, Barcelona - Caracas - México, Ariel, 1978), p. 639. Llama la atención que en el epígrafe y en el cuerpo de este fragmento del Liber iudiciorum se aluda a los notarios. En opinión de Marlasca, tal referencia no debe entenderse en el sentido moderno de un funcionario dotado de publica fides, encargado de garantizar la autenticidad de los documentos. Véase Marlasca Martínez, Olga, cit. (n. 13), p. 227.

${ }^{66} \mathrm{Cfr}$. Liber Iudiciorum 7,5,2.

${ }^{67} \mathrm{Cfr}$. Liber Iudiciorum 7,5,2. 
la falsificación de objetos específicos (testamentos, edictos, documentos burocráticos, entre otros), aquí se sanciona la falsedad recaída en soportes documentales concebidos de una manera más general. Ello no obsta a la existencia de diversas categorías de documentos, que pueden distinguirse dentro de dicho concepto genérico, como ocurrió, precisamente, a propósito de los documentos regios.

Según Alejandre, tal generalización del objeto material de los comportamientos falsarios se basa, fundamentalmente, en dos razones: primero, en el uso más extendido de nuevos materiales para la documentación de las relaciones jurídicas (como el cuero o el pergamino ${ }^{68}$, que dejaron en un segundo plano, por ejemplo, a los materiales utilizados para la confección de testamentos, edictos y documentos burocráticos en Roma. Segundo, en la paulatina pérdida de importancia de los sellos como garantía de que el contenido de los documentos permanecía inmutable ${ }^{69}$.

En la etapa posterior a la pérdida de vigencia del Liber iudiciorum y, particularmente, en lo que se conoce como periodo altomedieval, se reafirma lo señalado en cuanto a la fragmentariedad, dispersión y falta de certeza sobre la normativa aplicable $^{70}$. No obstante, como pone en evidencia Alejandre, esta es una fase en la que abundan los comportamientos falsarios recaídos en documentos, lo que se explica por el "valor privilegiado" de que gozaba el documento en tanto instrumento probatorio ante los tribunales ${ }^{71}$. Con todo, el castigo penal de dichas conductas, como nos informa el mismo Alejandre, se vio dificultado debido a que muchos de los comportamientos falsarios eran cometidos por monjes al interior de los centros monacales ${ }^{72}$.

En cuanto a los documentos que eran objeto de falsificación, destacan cartas de inmunidad o de privilegios, donaciones, diplomas, entre otros ${ }^{73}$. En relación con las conductas cometidas -aunque no necesariamente sancionadas- estaría la consistente en interpolar documentos o la de redactar otros apócrifos ${ }^{74}$.

El castigo penal de los comportamientos falsarios vuelve a adquirir importancia en virtud de la vigencia de los fueros extensos, así como de la legislación territorial que, entre otras cosas, sancionó falsedades realizadas por notarios ${ }^{75}$. Así, por ejemplo, en el Fuero de Cuenca, se castiga al notario que en el "libro de los juicios" -noción que puede ser entendida como equivalente a la de expediente- rallare alguna cosa o pusiere más en él ${ }^{76}$. Esta misma norma se replica en el Fuero de Baeza ${ }^{77}$.

${ }^{68}$ Véase Alejandre, J. A., cit. (n. 6), pp. $134 \mathrm{s.}$

${ }^{69}$ Cfr. Alejandre, J. A., cit. (n. 6), p. 135.

${ }^{70}$ Sobre las posibles causas de dicha fragmentariedad véase AlejANDRE, J. A., cit. (n. 6), p. 147.

${ }^{71}$ Ibíd., pp. 147 y s.

${ }^{72}$ Ibíd., p. 148.

${ }^{73}$ Ibíd., p. 148.

${ }^{74}$ Ibíd., p. 148.

${ }^{75}$ Véase Lalinde Abadía, J., cit. (n. 67), p. 639.

${ }^{76}$ Fuero de Cuenca, XVI,29 (444,446): "De pena infidelis notarij. Si notarius de falsitate, aut defraudatione conuictus fuerit usque ad centum menkales, pectet eos duplatos ut latro; a centum et supra, si deprehensus fuerit in fraudem, aut in libro indiciorum aliquid abraserit, uel apposuerit, abscidatur ei pollex dexter, et dampnum quod fecerit, pectet duplatum".

77 "Fuero de Baeza", 425 (a) y (b): "De la pena del falso escriuano. (a) Si el escriuano de false- 
Por su parte, en la normativa contenida en el Fuero Real, destaca la existencia de un título especial (XII), dedicado al castigo de los falsarios en general y de las escrituras falsas. En este título se sanciona la falsedad recaída en diversos objetos materiales, a saber, escrituras notariales ${ }^{78}$, sello del rey $^{79}$, documentos y sellos que no tienen el carácter de regios ${ }^{80}$, documentos relativos a determinados actos jurídicos ${ }^{81}$, así como documentos del rey ${ }^{82}$.

En relación con las conductas sancionadas, éstas giran en torno a los comportamientos de hacer o forjar, o bien, de mudar, fuera de diversas variantes de uso de documentos falsos, tales como leerlos o mostrarlos en juicio.

Finalmente, en la regulación consagrada en las Partidas, se contempla la falsedad de documentos del Papa y del Rey, abarcando cartas, privilegios, bulas y $\operatorname{sellos}^{83}$. Asimismo, se castiga la falsedad de otra clase de documentos, incluyendo privilegios, cartas, escrituras, cartas de testamento, escrituras de testamento, así como escrituras de pesquisa ${ }^{84}$. Además de dichos supuestos, se consagra la falsedad de bulas y de sellos ${ }^{85}$.

En cuanto a los comportamientos sancionados, las Partidas, a diferencia de las fuentes que veníamos analizando, establecen un concepto general de falsedad, que se define como mudamiento de la verdad ${ }^{86}$. Tal mudamiento de la verdad, según dicho cuerpo normativo, puede tener lugar de diversas maneras, por ejemplo, forjar, tarjar, cancelar o alterar ${ }^{87}$. A ellos se agregan otros comportamientos, que no son estrictamente falsarios, como hurtar, esconder, destruir y despojar ${ }^{88}$.

En el desarrollo histórico de las falsedades documentales, las Partidas pueden ser consideradas como un puente entre la regulación romana y los posteriores cuerpos normativos influidos por ella y el periodo de la codificación ${ }^{89}$.

dat o de enganno fuere prouado fasta en .C. mencales, peche los duplados cuemo ladron. (b) De.C. arriba, si preso fuere en enganno o en el libro del fuero alguna cosa radiere o annadiere, taien le el pulgar diestro, (...) el danno que por ende uiniere peche .l duplado."

${ }^{78} \mathrm{Cfr}$. Fuero Real, IV,12,1. Esta conducta debía ser cometida por notarios, que tenían una regulación especial en el libro I, título $7^{\circ}$ del mismo Fuero.

${ }^{79} \mathrm{Cfr}$. Fuero Real, IV,12,2 (comportamiento que debía ser cometido por clérigos) y IV,12,6 (comportamiento que podía ser cometido por cualquiera).

${ }^{80} \mathrm{Cfr}$. Fuero Real, IV,12,4. Esta conducta podía ser cometida por cualquiera. Tratándose de la falsificación de sellos que no tienen el carácter de regios, cometida por clérigos, el comportamiento debía ser sancionado sobre la base de lo dispuesto en IV,12,2.

${ }^{81} \mathrm{Cfr}$. Fuero Real, IV,12,5. Por ejemplo, escrituras de compra o de donación. Este comportamiento podía ser cometido por cualquiera.

${ }^{82} \mathrm{Cfr}$. Fuero Real, IV,12,6. Esta conducta podía ser cometida por cualquiera. Tratándose de la falsificación de documentos del Rey cometida por clérigos, esta misma norma establece que el comportamiento debía ser sancionado sobre la base de lo dispuesto en IV,12,2.

${ }^{83}$ Cfr. Partidas, VII,7,6.

${ }^{84} \mathrm{Cfr}$. Partidas, VII,7,1.

${ }^{85} \mathrm{Cfr}$. Partidas, VII,7,4.

${ }^{86}$ Cfr. Partidas, VII,7,1. Véase también Quintano Ripollés, A., cit. (n. 61), p. 45 y Rojas, L. E., cit. (n. 6), pp. 551 ss.

${ }^{87}$ Cfr. Partidas, VII,7,1.

${ }^{88}$ Cfr. Partidas, VII,7,1.

${ }^{89}$ En términos similares RoJAS, L. E., cit. (n. 6), p. 551. Para la influencia del derecho romano en las Partidas véase GreEn, Stuart P., Deceit and the Classification of Crimes: Federal 
En el proceso de generalización del objeto material de las falsedades, al que aludimos supra, las diversas categorías de documento comienzan a reducirse, perfilándose así la dicotomía entre documentos públicos y documentos privados, de una manera semejante a como la entendemos hoy. Así: "[e]ntre los siglos IX y XIII fue cristalizando en Europa, pero especialmente en Italia, el llamado derecho consuetudinario o derecho común, sustituido después, poco a poco, por el derecho romano, pero que, entre tanto, tuvo grande importancia, y se diversificó no solo por regiones sino también por clases sociales, en forma que las consuetudines variaban de pueblo a pueblo y de clase a clase. Se formaron así los estatutos que, en materia de falsedad, se caracterizaron por conminar una pena más humana y porque, además, se fijó la distinción entre documentos públicos y documentos privados $[\ldots]]^{\prime \prime 0}$.

Cabe destacar que la preocupación de la doctrina medieval no se circunscribió sólo a sistematizar los diversos objetos materiales de los comportamientos falsarios. Por el contrario, los prácticos de la época contribuyeron al desarrollo de una teoría general de las falsedades y, entre ellas, las documentales, cuyo punto de partida fue el trabajo de los jurisconsultos romanos ${ }^{91}$. En esta labor sobresalen las figuras de Farinacio ${ }^{92}$, en Italia, y Carpzov $^{93}$, en Alemania, cuyos trabajos influyeron de manera relevante a los penalistas franceses del siglo XVIII, quienes se encargaron de plasmar la tradición romana-medieval en el proceso codificador ${ }^{94}$.

\section{El ObJeto MATERIAL DE LAS FALSEDADES DOCUMENTALES EN LA CODIFICACIÓN y SU RECEPCión EN El CÓdigo Penal CHILENo}

La regulación de las falsedades documentales en la época de la codificación se caracteriza, entre otras cosas, por haber asentado la distinción, en cuanto al objeto material del delito, entre documentos públicos y documentos privados. De gran relevancia en esta etapa es la normativa existente en el derecho francés, debido a la

Rule of Evidence $609(A)(2)$ and the Origins of "crimen falsi", en The Journal of Criminal Law \& Criminology, 90 (2000) 4, p. 1100.

${ }^{90}$ Romero Soto, Luis Enrique, La falsedad documental (3a edición, s. 1., Carvajal, 1982), p. 6.

${ }^{91}$ Sobre el punto véase MirTo, Pietro, La falsità in atti (3a edición, Milano, Giuffrè, 1955), pp. 23 ss.

${ }^{92}$ Quien formuló el concepto de falsedad que se utiliza hasta nuestros días. En efecto, según señala Farinacio en la Quaestio CL, $\$$ I: "1. Falsitatis materiam aggressurus praemittendum in primis censui, quid sit falsum; Qua in re aliqui dixerunt, simpliciter, falsitatem esse veritatis mutationem [...]. 2. Aliqui † autem dixerunt falsitatem esse mutationem veritatis dolose seu scienter factam [...]. 3. Alii $\dagger$ dixerunt, \& melius, falsitatem esse veritatis mutationem o in alterius praeiudicium factam [...]. Ergo vbi falsitas nemini affert preiudicium, non est punibilis. 4. Et aliqui $\dagger$ demum dixerunt falsitatem esse imitationem veritatis [...]”. Cfr. FARINACIUS, Prosperus, Liber V: De Falsitate \& simulatione, titulus XVI, en Operum criminalium. Pars sexta (Francofvrti, E Collegio Musarum Paltheniano, 1612), pp. 1 y 2.

${ }^{93}$ Quien, inspirado en la regulación romana, aborda en la Quaestio XCIII el "Falsi Crimin" y define la falsedad (véase número marginal 5) como "dolosam veritatis immutationem, in alterius praejudicium factam". Cfr. CARPZOV, Benedicto, Practicae novae imperialis saxonicae rerum criminalium (6 ${ }^{\mathrm{a}}$ edición, Wittebergae, Schumacheri, 1684), II, pp. 365 ss.

${ }^{94}$ En este sentido Quintano Ripollés, A., cit. (n. 61), pp. 39 s. 
influencia que éste tuvo en los códigos penales posteriores y -en lo que aquí interesa- en la sistemática del objeto material de las falsedades documentales punibles.

Según Chauveau y Helie, la distinción entre documentos públicos y privados se remonta, en el derecho francés, a un edicto de marzo de $1680^{95}$. Luego, dicho distingo pasó a ser incorporado a los diversos códigos penales franceses que utilizaremos de referencia ${ }^{96}$.

El primer cuerpo normativo que cabe destacar a este respecto fue el Code Pénal de 1791. Éste, en sus artículos 42 a 44, distinguió tres objetos materiales de comportamientos falsarios, a saber, escrituras privadas, letras de cambio u otros efectos de comercio o de banco, y escrituras auténticas y públicas ${ }^{97}$.

El Code Pénal de 1810, por su parte, estableció una sistemática mucho más desarrollada del objeto material de las falsedades ${ }^{98}$, diferenciando varias clases y subclases de documentos, las que, con matices, mantuvieron las distinciones asentadas en el Code Pénal de 1791. En este Código, los documentos que podían ser falsificados eran documentos públicos o auténticos (artículos 145 a 149); documentos de comercio o de banco, que eran asimilados a los documentos públicos ${ }^{99}$ (artículos 147 y 148); documentos privados (artículo 150); pasaportes, permisos de caza, hojas de ruta y certificados (artículos 149, 153 a 162).

En este periodo se recibe el concepto de falsedad que había sido elaborado por los prácticos italianos $-\mathrm{y}$, principalmente, por Farinacio- que, como es sabido, se funda en la existencia de tres elementos: la alteración de la verdad, la intención fraudulenta o dolosa y el perjuicio ${ }^{100}$. La novedad que introdujo la doctrina francesa de la época fue haber planteado una distinción entre falsedad material e intelectual. Este distingo posibilitará una nueva forma de sistematizar las falsedades

${ }^{95}$ Cfr. Chauveau, Adolphe - Helie, Faustin, Théorie du Code Pénal (3a edición, Paris, Cosse et N. Delamotte, 1852), II, p. 383.

${ }^{96}$ Se debe reconocer, sin embargo, que existió una Ordenanza de 1737, que trató el castigo de las falsedades, centrándose más en la forma que adoptaba el comportamiento falsario, que en el objeto material del mismo, distinguiendo entre falsedad principal y falsedad incidental. Sobre ella véase Le Graverend, J. M., Traité de la législation criminelle (3 ${ }^{\text {a }}$ edición, Bruxelles, H. Tarlier, 1832), II, p. 207.

${ }^{97}$ Artículo 42 del Code Pénal de 1791: "Si ledit crime de faux est commis en écriture privée, la peine sera de quatre années de fers".

Artículo 43 del Code Pénal de 1791: "Si ledit crime de faux est commis en lettres de change ou autres effets de commerce ou de banque, la peine sera de six années de fers".

Artículo 44 del Code Pénal de 1791: "Si ledit crime de faux est commis en écritures authentiques et publiques, la peine sera de huit années de fers".

${ }^{98}$ Cfr. Merlin, M. - Rondonneau, L., Table générale alphabétique et raisonnée des matières contenues dans le répertoire de jurisprudence et dans le recueil alphabétique des questions de droit (Paris, Garnery, 1828), p. 316. Véase también Garraud, René, Traité théorique et pratique du droit pénal Français (Paris, Larose, 1899), III, p. 598.

${ }^{99}$ En este sentido Garraud, R., cit. (n. 100), p. 625.

${ }^{100}$ Véase Garraud, R., cit. (n. 100), pp. 495 y ss., aludiendo a la evolución de dicho concepto sobre la base de lo regulado en el Derecho romano. Este análisis le lleva a plantear un concepto de falsedad en los siguientes términos: "Le faux se constitue par une altération de la vérité dans un écrit, altération portant sur des fails que cet écrit était apte à prouver, susceptible de causer un préjudice et commise avec une intention frauduleuse" (cfr. La p. 497 de la obra citada). 
documentales, basada no tanto en el objeto material de las mismas, sino que en los comportamientos falsarios recaídos en documentos.

La aludida distinción se encontraría implícita en las modalidades de comisión establecidas en los artículos 145, 146 y 147 del Code Pénal de 1810. La falsedad material se concibe como la fabricación o alteración, total o parcial, de la pieza de que se trate, susceptible de ser reconocida, constatada o demostrada físicamente por una operación o por un procedimiento cualquiera ${ }^{101}$. Por su parte, la falsedad intelectual consiste en la alteración, no de la escritura del acto, sino que de su sustancia, esto es, no de su forma material, sino que de las cláusulas contenidas en el documento ${ }^{102}$.

Siguiendo la sistemática planteada por los Códigos franceses y, muy especialmente, por el de 1810, el Código Penal español de 1822 contempló una serie de supuestos de falsedad, distinguiendo entre falsedades recaídas en escrituras, en actas judiciales o en otros documentos públicos o de comercio (capítulos $3^{\circ} \mathrm{y}$ $4^{\circ}$ del título $\left.5^{\circ}\right)^{103}$. Una particularidad que presenta este Código es que enuncia diversas hipótesis que considera dentro de las categorías antes mencionadas. Así, por ejemplo, tratándose de la falsedad de documentos públicos, incluye escritura pública y auténtica; testimonio o certificación; acta judicial; partida de casamiento, muerte, nacimiento o bautismo; o acuerdos de autoridad pública de la misma clase; libros protocolos o procesos, después de estar cerrados; signo o sello (artículo 398); documentos oficiales, entre los que incluye libros o asientos de oficina o establecimiento público, títulos, certificaciones o cartas de pago (artículo 400); documentos públicos extranjeros (artículo 407); documentos privados (artículo 408); marcas, sellos, contrasellos o contraseñas de fábrica (artículo 409); certificado de médico (artículo 412); certificado de profesor (artículo 413).

En cuanto a los comportamientos sancionados, el Código Penal español de 1822 consagra un sinnúmero de comportamientos falsarios que pueden recaer sobre los aludidos objetos, expresión de la casuística que va a caracterizar a la regulación hispana hasta el Código de 1995. En todo caso, dicho Código parte siempre de la base de que se cometa una "falsedad" sobre determinados objetos.

De otro lado, el Código Penal español de 1848 y su reforma de 1850 simplificó la sistemática del Código de 1822, estableciendo categorías más genéricas en relación con el objeto material de las falsedades documentales. En efecto, el libro II, en su título $4^{\circ}$, capítulo $4^{\circ}$, consagró tres secciones, referidas a documentos públicos u oficiales y de comercio (sección $1^{\mathrm{a}}$ ); documentos privados (sección $2^{\mathrm{a}}$ ); pasaportes y certificados (sección $3^{\mathrm{a}}$ ).

Cabe destacar que Pacheco, al reconstruir la historia del artículo 226 del Código de 1848-1850 -norma que regula la falsificación de documento público cometida por eclesiástico o empleado público-, hace alusión a varias de las fuentes que han

${ }^{101}$ Cfr. Chauveau, A. - Helie, F., cit. (n. 97), p. 333. Véase igualmente Rojas, L. E., cit. (n. 6), p. 558.

${ }^{102}$ Cfr. Chauveau, A. - Helie, F., cit. (n. 97), p. 333.

${ }^{103}$ Sobre la regulación de la falsedad documental en el Código Penal español de 1822 véase Fernández Pantoja, Pilar, Delito de falsedad en documento público, oficial y mercantil (Madrid, Marcial Pons, 1996), pp. 15 s. 
sido citadas en el presente trabajo, concretamente, a los Digesta, al Fuero Juzgo, al Fuero Real, a las Partidas y al Código Penal napoleónico. Lo anterior se repite en dicha obra, con algunos matices respecto de las fuentes citadas, a propósito de los restantes tipos de falsedad documental regulados en dicho Código ${ }^{104}$.

Por otro lado, al igual que el Code Pénal de 1810, este Código se caracteriza por abordar de manera separada (en capítulos distintos) la falsificación de sellos y marcas, y la falsificación de documentos ${ }^{105}$. Con esto, la falsedad documental, aunque sigue siendo tratada junto a esos otros objetos, deja de estar confundida con ellos, como si fuesen un solo objeto material de comportamientos falsarios. De esta forma, se marca una diferencia respecto de lo que ocurría tanto en el derecho romano, como en el derecho medieval.

En lo que respecta al Código Penal chileno, para establecer una vinculación con la normativa que le sirvió de referencia, deben tenerse en cuenta las principales fuentes consultadas por la Comisión Redactora de dicho Código. Sobre esta cuestión, como expresa Matus, los miembros de la Comisión Redactora coincidieron en un punto fundamental, a saber, "la elección de un modelo legislativo avanzado para su época, el Código Penal español de 1850, teniendo a la vista su fuente, el de 1848; y de una obra epigonal para su valoración crítica: El Código penal concordado y comentado, de Pacheco" ${ }^{106}$.

La regulación de los delitos de falsedad documental no escapa a lo afirmado por dicho autor. Es así como en la sesión 42a de 5 de junio de 1871, la Comisión Redactora del Código Penal chileno, a sugerencia de Osvaldo Rengifo, acordó no formar un título separado para la falsificación de documentos en general, sino que regular esta materia como una parte del título $4^{\circ}$ del libro II, sobre delitos contra la fe pública, dividiéndolo en dos párrafos distintos: uno relativo a los instrumentos públicos, auténticos y partes telegráficos; otro relativo a los documentos privados $^{107}$. Esto se diferencia de lo acordado inicialmente ${ }^{108}$.

${ }^{104}$ Cfr. Pacheco, Francisco, El Código Penal comentado y concordado (6a edición, Madrid, Imprenta y Fundición de Manuel Tello, 1888), II, pp. 296 y ss. En términos similares véase Cuello Calón, Eugenio, Derecho penal. Parte especial. Revisado y puesto al día por César Camargo Hernández (reimp. de la 14a edición, Barcelona, Bosch, 1980), II, p. 213.

${ }^{105}$ Ponen en evidencia esta característica Antón Oneca, J. - Rodríguez Muñoz, J. A., Derecho penal. Parte especial (Madrid, s. e., 1949), II, p. 112.

${ }^{106}$ Matus, Jean Pierre, Evolución histórica de la doctrina penal chilena desde 1874 hasta nuestros dias (Santiago, LegalPublishing, 2011), pp. 171 s. (cursiva en el original).

${ }^{107}$ Véase Rivacoba y Rivacoba, Manuel (director), Código Penal de la República de Chile y Actas de las Sesiones de la Comisión Redactora del Código Penal Chileno (Valparaíso, Edeval, 1974), p. 331.

${ }^{108}$ En efecto, en la sesión $41^{\text {a }}$, de 2 de junio de 1871, la Comisión Redactora del Código Penal chileno discutió acerca del contenido del que actualmente es el título $5^{\circ}$ del libro II de dicho cuerpo normativo, al que decidió asignar como epígrafe "De la falsificación de documentos". Junto con ello, se acordó establecer dos párrafos, el primero llamado: "De la falsificación de instrumentos públicos o auténticos i de partes telegráficos"; el segundo llamado: "De la falsificación de instrumentos privados”. La Comisión Redactora dejó expresa constancia de que la preferencia de utilizar estas denominaciones, en lugar de las establecidas en los Códigos Penales belga y español, obedeció a adecuar la nomenclatura a la contenida en el Código Civil chileno. Cfr. Rivacoba y Rivacoba, M., cit. (n. 109), p. 330. 
La vinculación que existe entre el Código Penal chileno y el Código Penal español de 1848-1850 es destacada por Lazo quien, al analizar el origen de las disposiciones contenidas en los actuales párrafos 4,5 y 6 . del título $4^{\circ}$ del libro II, evidencia que casi la totalidad de ellas tiene su raíz en alguna disposición del Código Penal español ${ }^{109}$, con uno que otro matiz extraído del Código Penal belga de 1867. Lo dicho sólo encuentra excepción en lo dispuesto en los artículos 195 (sobre falsedad de partes telegráficos) y 196 (sobre uso malicioso de documento público) que, según el mismo autor, se basaron únicamente en disposiciones análogas del Código Penal belga de $1867^{110}$.

Esta filiación histórica del Código Penal chileno respecto de los Códigos Penales español de 1848-1850 y belga de 1867 permite establecer un continuo en la regulación positiva de las falsedades documentales y, con ello, del objeto material de las mismas ${ }^{111}$. Lo anterior se fundamenta en que el Código Penal español de 1848-1850 tuvo a su vez como principal fuente normativa al Code Pénal de 1810, el que por su parte se nutrió de todo el acervo proveniente de la tradición jurídica medieval y romana relativa a las falsedades documentales. Algo similar aconteció con el Código Penal belga de 1867 que, a juicio de Quintano Ripollés, también se basó en el Code Pénal de $1810^{112}$ y, de esta forma, en la tradición jurídica medieval y romana recientemente aludidas.

Así, la sistemática plasmada en el Código Penal chileno de 1874 consideró como objetos materiales de comportamientos falsarios a los documentos públicos y oficiales (artículos 193 y 194); a los partes telegráficos (artículo 195); a los documentos privados, entre ellos, los mercantiles (artículo 197); a los pasaportes o portes de armas (artículos 199 y 200); y a los certificados (artículos 202-205).

En cuanto a la regulación del comportamiento falsario recaído en dichos objetos, el Código Penal chileno siguió una sistemática muy similar a la del Code Pénal de 1810 y a la del Código Penal español de 1848-1850. En efecto, el artículo 193 del Código Penal patrio, de manera análoga a los aludidos Códigos, contempla un catálogo de conductas, al cual luego se remiten las falsedades recaídas en los restantes objetos. Sobre la base de esta sistemática han surgido, en la doctrina nacional, discusiones similares a las existentes en el Código Penal francés y español, por ejemplo, las relativas a la distinción entre falsedades materiales e intelectuales

${ }^{109}$ Fernández destaca, dentro de las diferencias entre el Código Penal chileno y el Código Penal español de 1848-1850, la supresión por parte de la Comisión Redactora de las palabras "u oficiales" en el epígrafe del párrafo 4 del título $4^{\circ}$ del libro II. Sin perjuicio de ello, se copió literalmente el número 8 del artículo 193 chileno del número 8 del artículo 226 español. También se eliminó del epígrafe las palabras "i de comercio", porque dicho objeto se reguló en el párrafo siguiente, junto con la falsificación de instrumentos privados. Cfr. Fernández, Pedro Javier, Código Penal de la República de Chile, Esplicado i Concordado (Santiago, Imprenta, Litografía i Encuadernación Barcelona, 1899), p. 322.

${ }^{110}$ Véase LAZO, Santiago, Los códigos chilenos anotados. Código penal: orígenes, concordancias, jurisprudencia (Santiago, Poblete Cruzat Hnos. Editores, 1915), pp. 172-180.

${ }^{111}$ En el mismo sentido Fuensalida, Alejandro, Concordancias i comentarios del Código Penal chileno (Lima, Imp. Comercial Calle del Huallaga N. 139, 1883), p. 136.

${ }^{112}$ Véase Quintano Ripollés, A., cit. (n. 61), p. 56. 
(ideológicas) y a la procedencia del castigo de estas últimas respecto de objetos materiales distintos del documento público ${ }^{113}$.

En consecuencia, la evolución histórica de las falsedades documentales, desde el punto de vista del objeto material de las mismas, no debe abordarse de manera parcelada, pues si bien es posible diferenciar, por ejemplo, la regulación contenida en la lex Cornelia, de aquella consagrada en los modernos códigos, existen aspectos comunes, que se han mantenido invariablemente hasta nuestros días. Uno de ellos es el castigo penal de comportamientos falsarios recaídos en objetos de relevancia para el desarrollo de las relaciones intersubjetivas al interior del tráfico jurídico, v.gr. testamentos y ciertos edictos en Roma, documentos regios en la época medieval, documentos públicos en la etapa codificadora.

Otro de dichos aspectos es que la selección de los objetos materiales de los comportamientos falsarios tiene en cuenta la posibilidad perpetuadora del contenido y la identificación de su autor, lo que explica el castigo de falsedades recaídas en soportes idóneos para cumplir esas funciones, tales como piedra, tablilla, papiro, pergamino o papel.

Finalmente, destaca la diferenciación que se efectúa respecto de documentos con una eficacia probatoria reforzada. Ello explica, por ejemplo, que inicialmente en Roma sólo se haya reconocido, además de la falsificación de testamentos, la de documentos "cum consignatione"; o que en la época medieval se haya conferido un estatuto especial a la falsedad recaída en documentos y sellos reales; o, en fin, que en la etapa de la codificación se haya atribuido esa misma eficacia a los documentos públicos, en oposición a los de carácter privado.

\section{BiBLIOGRAFÍA}

Alejandre, Juan Antonio, Estudio histórico del delito de falsedad documental, en Anuario de Historia del Derecho Español, 42 (Madrid, 1972).

Antón Oneca, J. - Rodríguez Muñoz, J. A., Derecho penal. Parte especial (Madrid, s. e., 1949), II.

ArCHI, Gian Gualberto, Problemi in tema di falso nel diritto romano, en EL MISMO, Scritti di diritto romano (Milano, Giuffrè, 1981), III.

Arrimadas García, Alfonso, Consideraciones en torno a la falsificación de moneda, en Calzada GonzÁlez, Aránzazu - CAMACHO de los Ríos, Fermín (coordinadores), El derecho penal: De Roma al derecho actual. VII Congreso Internacional y X Iberoamericano de derecho Romano (Madrid, Edisofer, 2005).

Bühler, G., The Laws of Manu, en Müller, F. Max (editor), The Sacred Books of the East (Oxford, Clarendon Press, 1886), XXV.

CARPzov, Benedicto, Practicae novae imperialis saxonicae rerum criminalium ( $6^{\mathrm{a}}$ edición, Wittebergae, Schumacheri, 1684), II.

Carvajal, Patricio Ignacio, El "receptum nautarum" y el papiro Grenf. II 108, en Revista de Estudios Histórico-Jurídicos, 28 (Valparaíso, Chile, 2006).

${ }^{113}$ Véase por todos ETCheberry, Alfredo, Derecho penal. Parte especial (reimp. de la $3^{\mathrm{a}}$ edición, Santiago, Editorial Jurídica de Chile, 1999), IV, p. 173. 
Castro Sáenz, Alfonso, Compendio histórico de derecho romano. Historia de la cultura jurídica europea ( $3^{a}$ edición, Madrid, Tébar, 2006), I.

Chauveau, Adolphe - Helie, Faustin, Théorie du Code Pénal ( $3^{\mathrm{a}}$ edición, Paris, Cosse et N. Delamotte, 1852), II.

Cuello Calón, Eugenio, Derecho penal. Parte especial. Revisado y puesto al día por César Camargo Hernández (reimp. de la 14ª edición, Barcelona, Bosch, 1980), II.

Cury, Enrique, Derecho penal. Parte general (10ª edición, Santiago, Ediciones Jurídicas UC, 2011).

De la Rada y Delgado, Juan de Dios, Elementos de derecho romano (Madrid, Imprenta de Repullés, 1857), II.

Díaz Bautista, Antonio, La acumulación de responsabilidades "ex delicto" en el Código de las "Siete Partidas"” en Glossae. Revista de Historia del Derecho Europeo, 3 (1992).

Díaz-Melián de Hanisch, Mafalda, Medios de prueba. El documento: evolución histórica. Roma, en La prueba y medios de prueba: De Roma al derecho moderno. Actas del VI Congreso Iberoamericano y III Congreso Internacional de Derecho Romano (Madrid, Servicio de Publicaciones Universidad Rey Juan Carlos, 2000).

Domingo, Rafael, Estudios sobre el primer título del edicto pretorio. Palingenesia y reconstrucción (Santiago de Compostela, Servicio de Publicaciones e Intercambio Científico Campus Universitario, 1995), III.

Domingo, Rafael, Observaciones para una nueva palingenesia del primer titulo del edicto perpetuo, en Escritos jurídicos en memoria de Luis Mateo Rodríguez (Santander, Universidad de Cantabria, Facultad de Derecho, 1993), II: "Derecho Privado".

DOMINGO, Rafael, Sobre las supuestas rúbricas edictales en el edicto del pretor, en Zeitschrift der Savigny-Stiftung für Rechtsgeschichte, Rom. abt., 108 (1991).

D'Ors, Álvaro, Contribuciones a la historia del "crimen falsi", en Studi in onore di Edoardo Volterra (Milano, Giuffrè, 1969), II.

D'Ors, Xavier, Antología de textos jurídicos de Roma (Madrid, Akal, 2001).

Etcheberry, Alfredo, Derecho penal. Parte especial (reimp. de la $3^{\text {a }}$ edición, Santiago, Editorial Jurídica de Chile, 1999), IV.

Farinacius, Prosperus, Liber V: De Falsitate \& simulatione, Titulus XVI, en Operum criminalium. Pars sexta (Francofvrti, E Collegio Musarum Paltheniano, 1612).

Fernández, Pedro Javier, Código Penal de la República de Chile, Esplicado i Concordado (Santiago, Imprenta, Litografía i Encuadernación Barcelona, 1899).

Fernández Pantoja, Pilar, Delito de falsedad en documento público, oficial y mercantil (Madrid, Marcial Pons, 1996).

Ferruccio, Giuseppino, Diritto penale romano (I singoli reati) (Padova, R. Zannoni, 1932), II.

Fuensalida, Alejandro, Concordancias i comentarios del Código Penal chileno (Lima, Imp. Comercial Calle del Huallaga N. 139, 1883).

Garraud, René, Traité théorique et pratique du droit pénal Français (Paris, Larose, 1899), III.

Green, Stuart P., Deceit and the Classification of Crimes: Federal Rule of Evidence $609(A)(2)$ and the Origins of "crimen fals", en The Journal of Criminal Law \& Criminology, 90 (2000) 4.

GuARINO, Antonio, De albo corrupto, en Index. Quaderni camerti di studi romanistici. International Survey of Roman Law, Omaggio a Francesco de Martino (Napoli, Jovene Editore, 1990). 
GuZMán Brito, Alejandro, Derecho privado romano (reimpresión de la $1^{\text {a }}$ edición, Santiago, Editorial Jurídica de Chile, 1997), II.

HeINECIO, J., Elementos del derecho romano según el orden de las Instituciones (trad. cast. de Vicente, J., Madrid, Imprenta de Don Pedro Sanz y Sanz, 1842).

HoEPfNer, Ludwig Julius Friedrich, Theoretisch-practischer Commentar über die Heineccischen Institutionen nach deren neuesten Ausgabe ( $8^{\mathrm{a}}$ edición, revisada, anotada y aumentada por Weber, Adolph Dieterich, Frankfurt am Main, s. e., 1804).

Hugo, Gustavo, Historia del derecho romano (trad. cast. de Casado Tello, M., Madrid, Establecimiento Tipográfico de D. R. R. de Rivera, 1850).

LaLinde Abadía, Jesús, Iniciación histórica al derecho español (2a edición, BarcelonaCaracas-México, Editorial Ariel, 1978).

Lara Peinado, Federico, Código de Hammurabi (Madrid, Tecnos, 1986).

LAzO, Patricio, La incertidumbre del texto en la experiencia jurídica romana. A propósito de D.1,2,2,1-3, en Revista Chilena de Derecho, 41 (2014) 3.

LAzo, Santiago, Los códigos chilenos anotados. Código penal: orígenes, concordancias, jurisprudencia (Santiago, Poblete Cruzat Hnos. Editores, 1915).

Le Graverend, J. M., Traité de la législation criminelle ( $3^{a}$ edición, Bruxelles, H. Tarlier, 1832), II.

Marino, Fabio, Il falso testamentario nel diritto romano, en MaYer-MaLY, Theo y otros (editores), en Zeitschrift der Savigny-Stiftung für Rechtsgeschichte, rom. Abt., 105 (1988).

Marlasca Martínez, Olga, La regulación de la falsificación de los documentos en el derecho romano y en la Ley de los Visigodos, en Estudios de Deusto. Revista de la Universidad de Deusto, 47 (1999) 1.

Martínez Martínez, Faustino, El tránsito de la oralidad hacia la escritura en la experiencia jurídica del siglo XIII: ejemplo sajón e hipótesis castellana (parte primera), en Cuadernos de Historia del Derecho, 13 (2006).

Mateo Sanz, Antonio, Documentos administrativos como elementos de prueba en el proceso privado romano, en La prueba y medios de prueba: De Roma al derecho moderno. Actas del VI Congreso Iberoamericano y III Congreso Internacional de derecho Romano (Madrid, Servicio de Publicaciones Universidad Rey Juan Carlos, 2000).

Matus, Jean Pierre, Evolución histórica de la doctrina penal chilena desde 1874 hasta nuestros días (Santiago, LegalPublishing, 2011).

Mayer-Maly, Theo, "Transscribere", en Avenarius, Martin - Meyer-Pritzl, Rudolf - MÖller, Cosima (editores), “Ars Iuris”. Festschrift für Okko Behrends zum 70. Geburtstag (Göttingen, Wallstein, 2009).

Merlin, M. - Rondonneau, L., Table générale alphabétique et raisonnée des matières contenues dans le répertoire de jurisprudence et dans le recueil alphabétique des questions de droit (Paris, Garnery, 1828).

MirTo, Pietro, La falsità in atti (3a edición, Milano, Giuffrè, 1955).

Mommsen, Teodoro, El derecho penal romano (trad. cast. de Dorado, P., Madrid, La España Moderna, 1898), II.

NúNEZ MARTí, Amparo, "Crimen falsi": derecho romano y nueva ley de enjuiciamiento civil, en La prueba y medios de prueba: De Roma al derecho moderno. Actas del VI Congreso Iberoamericano y III Congreso Internacional de derecho Romano (Madrid, Servicio de Publicaciones Universidad Rey Juan Carlos, 2000).

Pacheco, Francisco, El Código Penal comentado y concordado (6a edición, Madrid, Imprenta y Fundición de Manuel Tello, 1888), II. 
Quintano Ripollés, Antonio, La falsedad documental (Madrid, Reus, 1952).

Rivacoba y Rivacoba, Manuel (director), Código Penal de la República de Chile y Actas de las Sesiones de la Comisión Redactora del Código Penal Chileno (Valparaíso, Edeval, 1974).

Rojas, Luis Emilio, Historia dogmática de la falsedad documental, en Revista de Derecho de la Pontificia Universidad Católica de Valparaíso, 39 (Valparaíso, Chile, 2012).

Romero Soto, Luis Enrique, La falsedad documental (3a edición, s. 1., Carvajal, 1982).

SANMARTín, Joaquín, Códigos legales de tradición babilónica (Madrid, Trotta, 1999).

SANTALUCIA, Bernardo, Studi di diritto penale romano (Roma, L'Erma di Bretschneider, 1994).

VINNIO, Arnoldo, Comentario académico y forense del célebre jurisconsulto Arnoldo Vinnio á los cuatro libros de las instituciones imperiales de Justiniano (Barcelona, Librería de D. J. Oliveres, 1867), II. 